\title{
ВКЛАД ЭКОНОМИЧЕСКОЙ И СОЦИАЛЬНОЙ КОМИССИИ ДЛЯ ЗАПАДНОЙ АЗИИ ООН В РАЗВИТИИ СОТРУДНИЧЕСТВА МЕЖДУ АРАБСКИМИ СТРАНАМИ ПО ВОПРОСАМ ПРАВ ИНВАЛИДОВ
}

\author{
(c) 2020 Яковлева Е.Н. \\ кандидат юридических наук, доцент кафедры теории государства и права и основ правоведения \\ Юридического института \\ СГУ им. Питирима Сорокина, Россия, Сыктывкар \\ E-mail: egenyn@yandex.ru
}

В статье рассматриваются основные направления деятельности ЭСКЗА по содействию арабским странам в построении национальной политики, учитывающей интересы инвалидов. Проблема защиты прав инвалидов является актуальной для стран любого региона. Но в странах Западной Азии, как показывается в статье, она стоит особо остро. Научная новизна настоящей работы заключается в отсутствии научных исследований, затрагивающих региональный опыт сотрудничества по проблематике инвалидности. С применением формально-юридического метода в работе анализируется уникальный опыт ЭСКЗА по совершенствованию региональной статистики инвалидности, а также иная деятельность, помогающая арабским государствам внедрить социальную модель инвалидности в национальный стандарты социальной политики. По итогам исследования делается вывод об увеличении роли ЭСКЗА в содействии продвижению международных стандартов прав инвалидов в национальной политике государств региона.

Ключевые слова: инвалиды, права инвалидов, ЭСКЗА, арабские государства

Составной частью системы ООН являются региональные комиссии, цель которых заключается в содействии социальному и экономическому развитию соответствующих регионов и в укреплении экономических отношений стран каждого региона между собой и с другими странами мира.

В ООН действуют несколько региональных комиссий Экономического и Социального совета (ЭКОСОС): Экономическая комиссия для Африки, Экономическая и социальная комиссия для Азии и Тихого океана, Европейская экономическая комиссия, Экономическая комиссия для Латинской Америки и Карибского бассейна, Экономическая и социальная комиссия для Западной Азии.

В целом все комиссии больше ориентируются на стимулирование экономического сотрудничества государств региона. И только две из них также предпринимают действия для выработки единых принципов социальной политики государств - это Экономическая и социальная комиссия для Азии и Тихого океана и Экономическая и социальная комиссия для Западной Азии (ЭСКЗА). В настоящей статье анализируется социальный аспект деятельности ЭСКЗА, а именно мероприятия комиссии в сфере улучше- ния положения инвалидов. Конечно, вопросы, связанные с обеспечением прав инвалидов, не стоят на первом месте в повестке работы ЭСК3А. Тем не менее, комиссия не оставила эту проблему в стороне и сыграла определенную роль в формировании новых подходов в решении проблематики инвалидности в регионе.

ЭСКЗА была образована в 1973 году как преемник Экономического и Социального Бюро ООН в Бейруте (ЮНЕСОБ). ЭСКЗА осуществляет свою деятельность в регионе Западной Азии и объединяет 20 арабских государств. Комиссия содействует согласованным действиям членов в области экономического и социального развития с помощью регионального и субрегионального сотрудничества и интеграции, выступает главным форумом по экономическому и социальному развитию региона в рамках системы ООН [1]. Основными целями ЭСКЗА являются:

- поддержка экономического и социального развития в странах-членах;

- содействие сотрудничеству между странами-членами;

- поощрение обмена опытом, передовой практикой;

- развитие региональной интеграции и обеспечение взаимодействия между Западной Ази- 
ей и другими регионами;

- повышение глобальной осведомленности об обстоятельствах и потребностях странчленов [2].

Не останавливаясь подробно на структуре комиссии, отметим только, что в ее составе есть отдел по вопросам социального развития, одной из функций которого является рассмотрение важных вопросов в сфере здравоохранения, образования, прав человека, прав ребенка, равенства между мужчинами и женщинами, социальных перемен [3].

Проблема прав инвалидов очень актуальная для государств Западной Азии. В государствах этого региона сохраняется неблагоприятная социальная обстановка: нездоровый образ жизни, нищета, политическая нестабильность, вооруженные конфликты и др. [11]. Низкий уровень уважения прав человека усугубляет и без того тяжелое положение социально незащищенных слоев населения, в том числе инвалидов. Число людей, имеющих инвалидность, в этом регионе растет. И, несмотря на то, что отдельные государства-члены ЭСКЗА принимают правовые акты в защиту прав инвалидов, однако в повседневной жизни ситуация в лучшую сторону не меняется. Положение инвалидов усложняется также тем, что традиционное общество стран Западной Азии не является терпимым к людям с особенностями и подвергает нападкам и гонениям людей с инвалидностью.

Согласно данным, опубликованным ЭСКЗА в 2018 году, уровень распространенности инвалидности в арабском регионе колеблется в диапазоне от 0,2 процента в Катаре до 5,1 процента в Марокко [8]. Такой разброс показателей обусловлен особенностями региона. В частности, существует методологические трудности сбора данных по инвалидам: государства используют разные подходы в определении того, что относится к «инвалидности», а также разные методы определения инвалидности. Во-вторых, отмечается тот факт, что арабское население относительно молодое и, следовательно, инвалидность среди молодого населения распространена меньше. В-третьих, в отдельных странах региона проживает большое количество рабочих-мигрантов, которые, как правило, не заявляют о своей инвалидности. В-четвертых, следствием вооруженных конфликтов является не только инвалидность, вызванная физическими увечьями, но также возникают психические и психологические расстройства, которые не учитываются как формы инвалидности и поэтому нигде не регистрируются.

ЭСКЗА в своей деятельности проблематику инвалидности не оставляет в стороне. Можно выделить несколько направлений работы комиссии.

В частности первые шаги комиссии заключались в организации международных конференций, форумов, где поднимались вопросы прав инвалидов. Например, в 1989 году ЭСКЗА организовала Конференцию о возможностях и потребностях инвалидов в регионе ЭСКЗА (г. Амман, 20-28 ноября 1989 г.), по результатам которой были разработаны основы планирования региональной деятельности в данной сфере.

По окончании Десятилетия инвалидов ООН (1983-1992 годы) под эгидой Королевы Иордании Нур Аль-Хусейн и ЭСКЗА состоялся Культурный форум в интересах людей с инвалидностью (г. Амман, 17-18 октября 1992 г.). На форуме была утверждена долгосрочная стратегия на период до 2010 года по поощрению прав человека людей с инвалидностью в регионе Западной Азии.

В начале XXI века в ОOH началась активная работа по разработке проекта всеобъемлющей конвенции о поощрении прав инвалидов и, как следствие, перед арабскими странами встал вопрос о необходимости совершенствования подходов в решении вопросов инвалидности.

В этой связи в 2002 году состоялась международная конференция по теме «Положение в области инвалидности в арабских странах: на пути к провозглашению Десятилетия инвалидов арабских стран» (г. Бейрут, 2-5 октября 2002 г.), в котором приняли участие представители 18 государств региона, эксперты, организации инвалидов, ЭСКЗА, местные, региональные и международные организации по вопросам инвалидов. Главным итогом конференции стало провозглашение Десятилетия инвалидов арабских стран 2004-2013 г.г. Основными целями провозглашения Арабского десятилетия инвалидов являются:

- изменение отношения общества к проблемам инвалидности и к инвалидам;

- обозначение решение проблем инвалидности в качестве одного из приоритетного направления государственной политики арабских стран;

- предоставление инвалидам скидки не менее $50 \%$ за плату пользованием наземным, мор- 
ским и воздушным транспортом в пределах территории любого арабского государства и между ними;

- поддержка семей инвалидов и содействие созданию организаций по защите интересов инвалидов;

- обучение и реабилитация инвалидов с использованием современных технологий и т.д. [7].

Провозглашение Арабского десятилетия инвалидов поставило решение проблем инвалидов в число приоритетных направлений политики правительств арабских стран. Однако отмечается, что, несмотря на обязательства, взятые арабскими странами в рамках регионального Десятилетия, инвалидность еще не в полной мере рассматривается как проблема прав человека. До сих пор в основе сбора статистических данных и принятия мер в рамках национальной политики лежат медицинские принципы реабилитации и ухода [11].

ЭСКЗА содействует продвижению и реализации инициатив ООН в Азиатском регионе. Комиссия поддерживает партнерские отношения с институтами ООН: ВО3, МОТ. Так, например, благодаря комиссии в 2003 году ООН смогла осуществить ряд инициатив в области создания доступной для инвалидов городской инфраструктуры в государствах Западной Азии [4].

Еще одним направлением работы ЭСКЗА является решение вопросов статистики по инвалидности.

Проблема статистики инвалидности является серьезной для стран региона. Как уже отмечалось, государства используют несогласованные и несопоставимые методы учета инвалидов. Роль ЭСКЗА в решении этой проблемы заключается в выработке единых подходов и методов по сбору указанных данных «для повышения сопоставимости и совершенствования отчетности на национальном уровне» [5]. В этой связи комиссия подготовила и опубликовала тематические исследования: «Arab Disability Statistics in Numbers 2017» («Инвалидность в арабских странах в цифрах») (E/ESCWA/SD/2017/Technical Paper 1), «Disability in the Arab Region 2018» («Инвалидность в Регионе арабских государств») (Е/ ESCWA/SDD/2018/1) и «Regional Guidebook to Improve Disability Data Collection and Analysis in the Arab Countries» (Региональное руководство по совершенствования сбора и анализа данных по инвалидности в арабских странах») (2018 г., Е/ ESCWA/SD/2018/MANUAL.1). Исследования слу- жат методологической основой для совершенствования подходов ведения статистики учета инвалидности.

В рамках ЭСКЗА действует Межучрежденческое совещание экспертов по совершенствованию статистики инвалидности в контексте достижения целей в области устойчивого развития [10], главная задача которого состоит в разработке системы показателей инвалидности для региона арабских стран и руководства по статистике инвалидности. В 2019 году Статистический отдел ЭСКЗА подготовил первую систему показателей инвалидности. Единая система показателей будет способствовать сбору более полных, достоверных, объективных данных об уровне инвалидности странах Западной Азии: «система поможет лицам, обеспечивающим подготовку данных, предоставить разработчикам политики ценную информацию более высокого качества, которая позволит добиться охвата всех инвалидов, где бы они ни находились» [5].

ЭСКЗА оказывает поддержку Межсессионной группе экспертов по вопросам инвалидности, которую она создала в 2017 году. Почти каждое государство-член комиссии является активным участником этой Группы. Участники обмениваются актуальными сведениями о внутрирегиональном и межрегиональном сотрудничестве. В мае 2018 года представители государственных органов собрались в Саудовской Аравии для рассмотрения вопроса о темпах перехода от «медицинской модели», в которой основное внимание уделяется физическим аспектам инвалидности, к «социальной модели» оценки инвалидности, в которой учитываются социальные аспекты и используется основанный на правах человека подход и классификационный инструмент ВОЗ [6].

ЭСКЗА также сотрудничает с другими региональными комиссиями ООН в осуществлении межрегионального проекта по выявлению передовой практики в разработке, реализации и финансировании схем социальной защиты. Конечной целью этого проекта является развитие региональной базы знаний о схемах социальной защиты и оказание поддержки инициативам на национальном уровне по передовому опыту поддержки инвалидов.

За последние годы произошли значительные изменения в институциональной и правовой базе, обеспечивающей защиту прав инвалидов в арабских странах. На региональном уровне 15 арабских стран подписали и 19 ратифицирова- 
ли Конвенцию о правах инвалидов. Кроме того, семь арабских стран подписали и восемь ратифицировали Факультативный протокол. Правительства разработали новые законы, стратегии и политику в поддержку инвалидов: 13 стран создали национальные координационные механизмы по вопросам инвалидности (в форме национальных советов по вопросам инвалидности); 12 арабских стран включили статьи об инвалидности в свои конституции; в 16 государствах региона приняты всеобъемлющие законы об инвалидности [9].

Указанные достижение, на наш взгляд, во много произошли благодаря деятельности ЭСКЗА. ЭСКЗА одна из немногих региональных комиссий ООН, кто содействует социальной интеграции, уделяя особое внимание инвалидам. Комиссия не принимает каких-либо императивных актов, обязывающих государств внедрять международные стандарты прав инвалидов. Она оказывает методическую, консультационную, техническую помощь государствам, ориентирует их на соблюдение принципов уважения прав инвалидов. С помощью политических методов ЭСКЗА помогает государствам-членам выделить приоритеты в сфере социальной политики, переформатировать национальные программы с учетом принципов инклюзивного общества. Комиссия является проводником инициатив ООН и его институтов. Почти все арабские государствачлены комиссии (кроме Судана) подписали или ратифицировали Конвенцию ООН о правах инвалидов. Поэтому главной задачей комиссии в настоящее время является оказать содействие государствам-членам по воплощению и претворению в жизнь норм Конвенции по правам инвалидов. Следовательно, роль ЭСКЗА как единой платформы, объединяющей интересы разных по экономическому и политическому уровням развития государств, по реализации концепции учета проблем инвалидов в национальной политике будет с каждым разом увеличиваться.

\section{Библиографический список}

1. Экономическая и социальная комиссия для Западной Азии (ЭСКЗА) https://www.un.org/ru/ecosoc/escwa/

2. ESCWA https://www.unescwa.org/about-escwa

3. Организационная структура секретариата Экономической и социальной комиссии для Западной Азии: Бюллетень Генерального Секретаря / Документ ООН ST/SGB/2002/16 от 27 декабря 2002 г. URL: https:// undocs.org/ru/ST/SGB/2002/16 (дата обращения 28.09.2020)

4. Прогресс, достигнутый в области обеспечения равных возможностей усилиями инвалидов, в интересах инвалидов и с участием инвалидов: Доклад Генерального Секретаря [Электронный ресурс] // Документ ООН A/AC.265/2003/3 от 7 апреля 2003 г. P. 16. URL: https://www.un.org/esa/socdev/enable/documents/ahcdocs03/ progeq-ru.pdf (дата обращения 28.09.2020)

5. Статистика инвалидности: Совместный доклад Генерального секретаря, Вашингтонской группы по статистике инвалидности и международных учреждений [Электронный ресурс] / Документ ЭКОСОС Е/ CN.3/2020/34 от 20 декабря 2019 г. C. 7. URL: https://millenniumindicators.un.org/unsd/statcom/51st-session/ documents/2020-34-DisabilityStats-R.pdf (дата обращения 14.10.2020)

6. Annual Report 2018: Technology For Development. [Электронный ресурс] ESCWA. 2018. P.36 https://www. unescwa.org/publications/annual-report-2018 (дата обращения 23.10.2020)

7. Arab Decade of Disabled Persons, 2003-2012 [Электронный ресурс] URL: https://www.un.org/esa/socdev/enable/ disarabdecade.htm (дата обращения 23.10.2020)

8. Disability in the Arab Region 2018. ESCWA. 2018. P. 14

9. Disability in the Arab World: From Charity to Agency. [Электронный ресурc] URL: https://www.unescwa.org/ disability-arab-world-charity-agency (дата обращения 28.10.2020)

10. Inter-agency and Expert Group Meeting on Improving Disability Statistics in the Sustainable Development Goals [Электронный ресурс] URL: https://www.unescwa.org/events/expert-group-meeting-improving-disabilitystatistics-sustainable-development-goals (дата обращения 28.10.2020)

11. Managing Change: Mainstreaming Disability into the Development Process / Economic and Social Commission for Western Asia (ESCWA) E/ESCWA/SDD/2012/Brochure.1. 28 June 2012. P 3. 